\title{
End-of-life care is an integral part of healthcare services
}

Helen YL Chan, RN PhD

The Nethersole School of Nursing, Faculty of Medicine, The Chinese University of Hong Kong

Correspondence to: helencyl@cuhk.edu.hk

Quality of death has gained considerable attention worldwide in acknowledging the limits of medicine. ${ }^{1}$ The care provided in the last phase of life is an imperative of healthcare services. End-of-life (EOL) care is often conflated with palliative care because both involve optimising the quality of life of people with life-limiting conditions. Palliative care denotes a holistic care approach that can be provided earlier in the disease trajectory in parallel with curative treatment. EOL care is time-specific, focusing on those with poorer prognosis and, based on clinical experience, death is estimated to occur in the following 12 months. ${ }^{2}$ In response to the global movement in promoting comfort and dignity at the end of life, the Food and Health Bureau of the Hong Kong SAR Government has launched a public consultation on EOL care, specifically on legislation related to advance directives and dying in place. ${ }^{3}$

In this issue of Asian Journal of Gerontology \& Geriatrics, two timely articles report on EOL care in Hong Kong. Lau et $\mathrm{al}^{4}$ explore the experiences of advance care planning (an important component of EOL care) among healthcare professionals in care home settings based on a medical-social collaboration model. The authors found that multidisciplinary collaboration, trained staff, and well-informed family members were facilitators. However, lack of public awareness and understanding, deferral of the planning process, and inadequate time and manpower were barriers that might hinder implementation of advance care planning beyond the pilot programme.

Fong et $\mathrm{a}^{5}$ conducted a survey on speech therapists about palliative care and report that relevant practice guidelines and training are lacking, resulting in inconsistencies in practice and concerns about legal liability. The authors' findings are consistent with those of Chan et $\mathrm{al}_{1}{ }^{6}$ who found that the overall development of EOL care is influenced by various factors at individual, organisational, legal, and sociocultural levels. Therefore, the recent public consultation is an opportune time for the government to overhaul development of EOL care in terms of policy, legislation, financial support, manpower planning, capacity building, and public education. The aim should be to create an environment conducive to person-centred, holistic, dignified, and accessible EOL care.

\section{REFERENCES}

1. The Economist Intelligence Unit. The 2015 Quality of Death Index. Lien Foundation; 2015.

2. National Institute for Health and Care Excellence. NICE Guideline on end of life care for adults: Service delivery. United Kingdom; 2019.

3. Food and Health Bureau. End-of-life care: legislative proposals on advance directives and dying in place. Hong Kong SAR Government; 2019.

4. Lau BHP, Luk JKH, Fong CHC, et al. Facilitators and barriers to advance care planning programmes targeting older care home residents: a qualitative study. Asian J Gerontol Geriatr 2019;14:81-8. Crossref

5. Fong R, Tsai CF, Wong WHS, Yiu OY, Luk JKH. Speech therapy in palliative care and comfort feeding: current practice and way ahead. Asian J Gerontol Geriatr 2019;14:61-8. Crossref

6. Chan HYL, Lee DTF, Woo J. Diagnosing gaps in the development of palliative and end-of-life care: a qualitative exploratory study. Int $J$ Environ Res Public Health 2019;17:E151. Crossref 